\title{
Free walking speeds on stairs: Effects of stair gradients and obesity of pedestrians
}

\author{
Taku Fujiyama and Nick Tyler
}

Centre for Transport Studies, University College London

Gower Street, London, WC1E 6BT United Kingdom

Corresponding author: taku.fujiyama@ucl.ac.uk

\begin{abstract}
Effects of stair gradients and obesity on walking speeds on stairs were empirically investigated. The participants included a group of elderly people $(n=18)$ and a group of young people $(n=15)$. They were asked to ascend/descend four staircases with different gradients, as well as to walk on a flat surface, at both normal and fast speeds. The study found the effects of stair gradients. When walking speeds on stairs are estimated, the gradient should be taken into account. In contrast, the study found no effect of overweight (or moderate obesity) on speeds.
\end{abstract}

\section{Introduction}

Walking speed is an important element of the walking characteristics of pedestrians. In order to run a pedestrian simulation model, it is necessary to determine free walking speeds. Free walking speeds are defined as the speed at which a pedestrian wishes to walk when there are no obstructions [1]. There have been a good number of studies on walking speeds (on flat surfaces) and some studies have investigated the effects of personal characteristics, such as age and gender, on walking speeds (e.g. [2]). These studies have shown that elderly people walk more slowly than young or middle-aged people and that women's walking speeds are slower than those of men. In fact, differences in walking speeds according to age and gender have also been investigated by physiologists (e.g. [3]).

Although their number is far less than studies on flat surfaces, there have been a few studies on free walking speeds on stairs. Stairs are an important element of transport facilities, such as transport terminals or stations, and when pedestrian movements in a whole facility or building are simulated, stairs have to be included. Fruin [4] showed that walking speeds decline according to age and that women showed a lower value than men. Templer [5] suggested an equation which estimates walking speeds on stairs based on the dimensions of stairs (i.e. treaddepth and riser-height). 
One issue that needs further investigation is how different are walking speeds on stairs from those on flat surfaces. In order to estimate walking speeds on stairs, many microscopic pedestrian simulation models use a "reduction coefficient", which is multiplied by walking speeds on flat surfaces. Knowledge of the difference in walking speeds between stairs and flat surfaces can help simulation modellers use a better coefficient. Another issue can be the effects of obesity. Obesity is an emerging problem in many developed countries. Obese pedestrians could walk slower than ordinary pedestrians, and an increase in the number of overweight pedestrians could change the capacity of pedestrian flow. Therefore, this study examines the following questions:

- How different are walking speeds on stairs from those on flat surfaces?

- Does overweight affect walking speeds? If so, how much?

Note that the definitions of walking speeds on stairs are as shown in Figure 1. In this paper, speeds on stairs mean horizontal walking speeds unless specified.

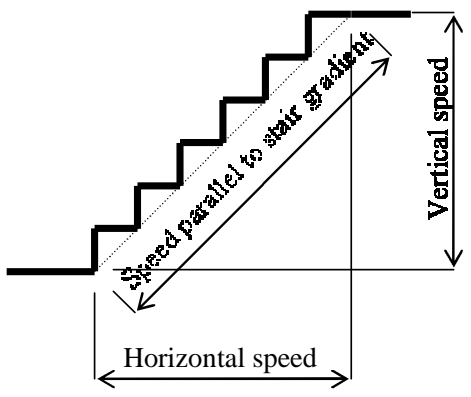

Fig. 1: Definitions of speeds on stairs

\section{Experiment data}

An experiment was conducted on four staircases with different gradients in a university campus (Table 1). The details of the experiment were published elsewhere [6]. In the experiment, each participant was asked to ascend and descend a flight of each staircase at his/her normal and fast walking speeds, which means that we measured four patterns of speeds for each participant: namely the normal ascending speed, the normal descending speed, the fast ascending speed and the fast descending speed. Each participant was asked to repeat this exercise on four staircases with different stair-gradients as well as to walk at normal and fast speeds on a flat surface. The experiment included two groups of participants: one consisted of people aged 60 or over, whereas the other consisted of university students and employees. The characteristics of the participants are displayed in Table 2. 
Table 1. The dimensions of the staircases used in the experiment

\begin{tabular}{llllllll}
\hline \multirow{2}{*}{ Staircase No. } & $\begin{array}{l}\text { Number } \\
\text { of steps }\end{array}$ & \multicolumn{2}{l}{ Proportion } & \multicolumn{3}{l}{ Total length } \\
\cline { 3 - 7 } & $\begin{array}{l}\text { Riser- } \\
\text { height }\end{array}$ & $\begin{array}{l}\text { Tread- } \\
\text { length }\end{array}$ & $\begin{array}{l}\text { Stair- } \\
\text { Gradient }\end{array}$ & $\begin{array}{l}\text { Horizontal } \\
\text { length }\end{array}$ & $\begin{array}{l}\text { Vertical } \\
\text { length }\end{array}$ & $\begin{array}{l}\text { Availability } \\
\text { of handrail }\end{array}$ \\
\hline Staircase 1 & 12 & 185 & 230 & 38.8 & 2.76 & 2.22 & $\checkmark$ \\
\hline Staircase 2 & 12 & 175 & 250 & 35.0 & 3.00 & 2.10 & $\checkmark$ \\
\hline Staircase 3 & 15 & 157 & 267 & 30.5 & 4.01 & 2.36 & $\checkmark$ \\
\hline Staircase 4 & 9 & 152 & 332 & 24.6 & 2.99 & 1.37 & $\checkmark$ \\
\hline Flat surface & - & & & 8.00 & - & $\mathbf{x}$ \\
\hline
\end{tabular}

Table 2. The characteristics of the participants

\begin{tabular}{lll} 
& Elderly & Young \\
\hline Sample number & 18 & 15 \\
\hline (male sample) & 6 & 7 \\
\hline (female sample) & 12 & 8 \\
\hline Age $(\mathrm{yrs})$ & $71 \pm 5.9$ & $34.5 \pm 12.7$ \\
\hline Height $(\mathrm{m})$ & $1.61 \pm 0.72$ & $1.74 \pm 0.82$ \\
\hline Weight $(\mathrm{kg})$ & $67.3 \pm 11.7$ & $66.4 \pm 13.9$ \\
\hline
\end{tabular}

Results are given as mean \pm SD.

\section{Results and Analysis 1: How walking speeds on stairs differ from those on a flat surface?}

Figure 2 shows the percentages of normal walking speeds on stairs of both ascending and descending in proportion to those on a flat surface. For each walking pattern (ascending or descending) of each participant group (elderly or young), percentages were calculated as

$$
\begin{aligned}
& p_{k}=\overline{v_{k n} / v_{f n}} \ldots \ldots \ldots(1) \\
& \text { where } \mathrm{p}_{\mathrm{k}} \text { : percentage for staircase } k \\
& \mathrm{v}_{\mathrm{kn}} \text { : walking speed on staircase } k \text { of participant } n \\
& \mathrm{v}_{\mathrm{fn}} \text { : walking speed on a flat surface of participant } n
\end{aligned}
$$

The figures suggest that percentages vary according to the stair gradient. Interestingly, a linear relationship can be seen between walking speeds and stairgradients.

Figure 3 shows the percentages of ascending speeds (both normal and fast) on stairs in proportion to speeds on a flat surface. Note that for each pedestrian, normal ascending or descending speeds were compared to the normal walking speed 


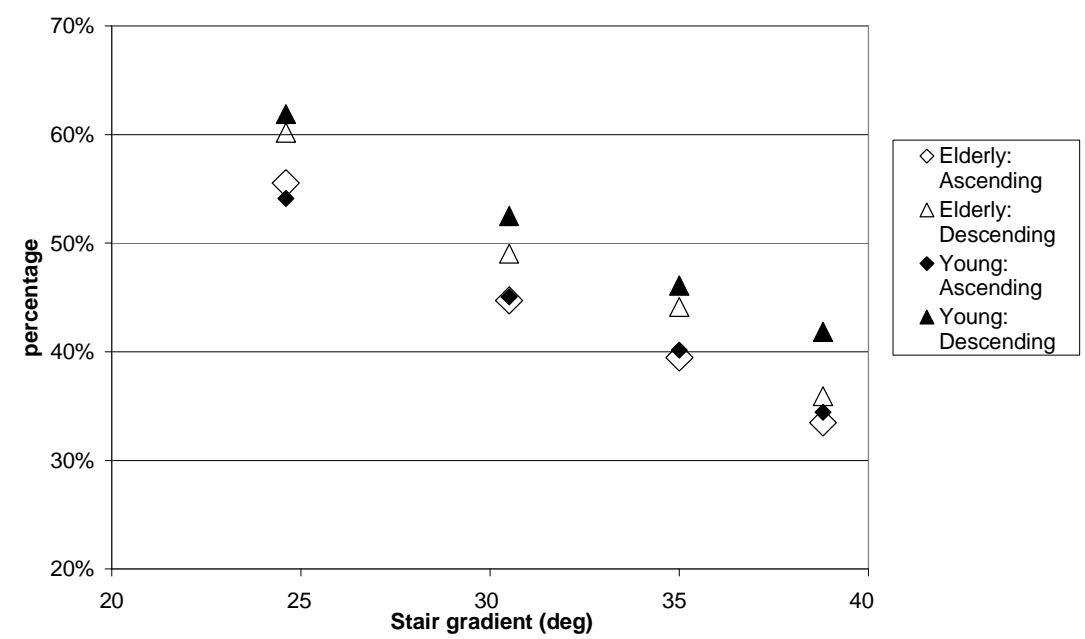

Fig. 2. Percentage of normal walking speeds on stairs to those on a flat surface

on a flat surface, whereas fast walking speeds were compared to the fast speed on a flat surface. Figure 4 shows those of descending speeds. For ascending speeds at the normal speed, the elderly participants showed similar values to those of the young participants, whereas for descending this is the case only when the gradient was not steep.

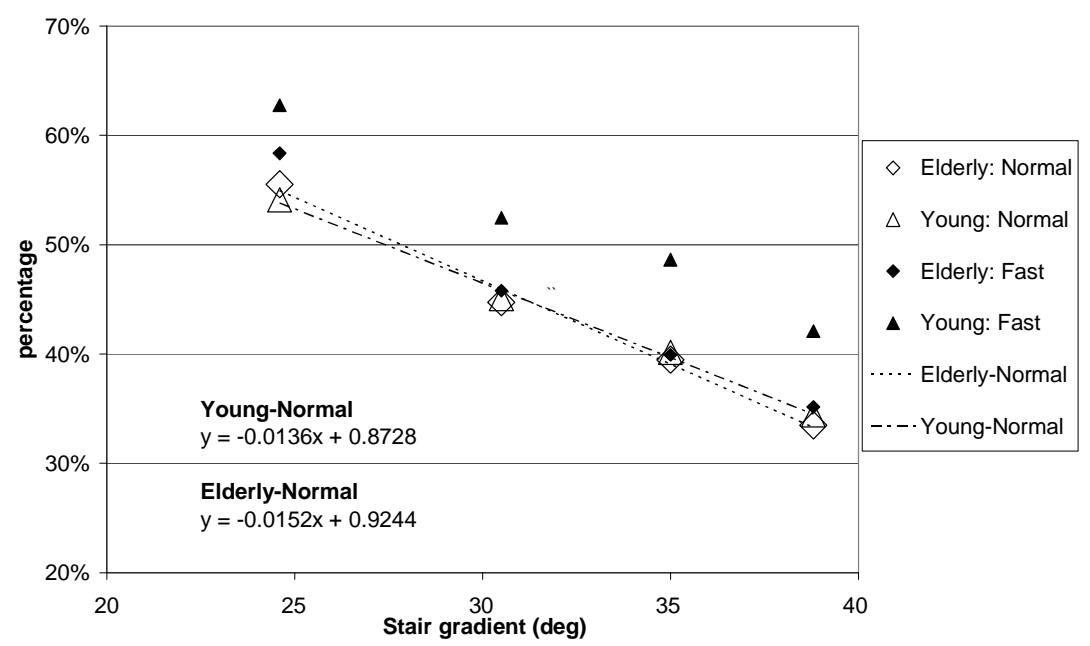

Fig. 3 . Percentage of ascending speeds on stairs to those on a flat surface 


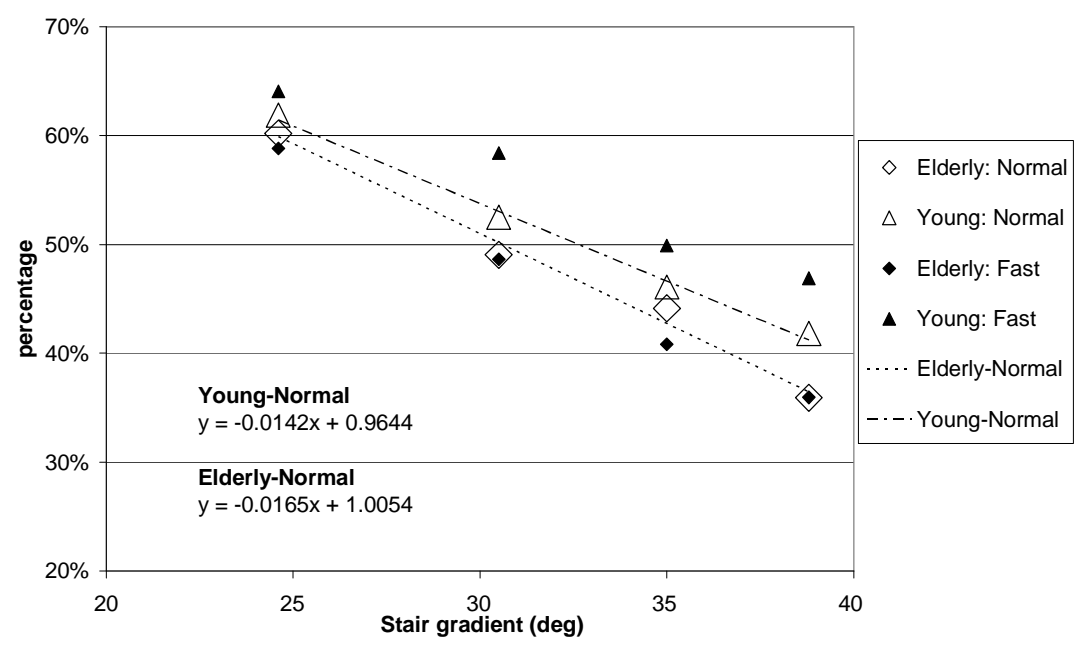

Fig. 4. Percentages of descending speeds on stairs to those on a flat surface

\section{Result and Analysis 2: Effects of overweight on walking speeds}

We use Body Mass Index (BMI) as the index of overweight. BMI is calculated as follows.

$$
B_{n}=W_{n} / H_{n}^{2} \cdots \cdots \cdots(3)
$$

$$
\begin{array}{lll}
\text { where } & \mathrm{B}_{\mathrm{n}}: & \text { Body Mass Index of participant } n\left(\mathrm{~kg} / \mathrm{m}^{2}\right) \\
& \mathrm{W}_{\mathrm{n}}: & \text { Weight of participant } n(\mathrm{~kg}) \\
& \mathrm{V}_{\mathrm{n}}: & \text { Height of participant } n(\mathrm{~m})
\end{array}
$$

BMI is commonly used as an indicator of obesity. According to WHO [7], a person with a BMI of 25 or more is regarded as being overweight. Figure 5 shows normal ascending speeds on Staircase 2 by BMI, whereas Figure 6 shows fast ascending speeds. We had hypothesised that overweight has negative effects on walking speeds, which can be described as a negative proportionate relationship between BMI and walking speeds. However, such a relationship is not seen in the figures.

The participants of each group (elderly and young) were divided into two subgroups: Normal and Overweight. The "Normal" groups consisted of participants 
with a Body Mass Index (BMI) of less than 25, the "Overweight" having 25 or more. Table 3 shows the profile of each subgroup.

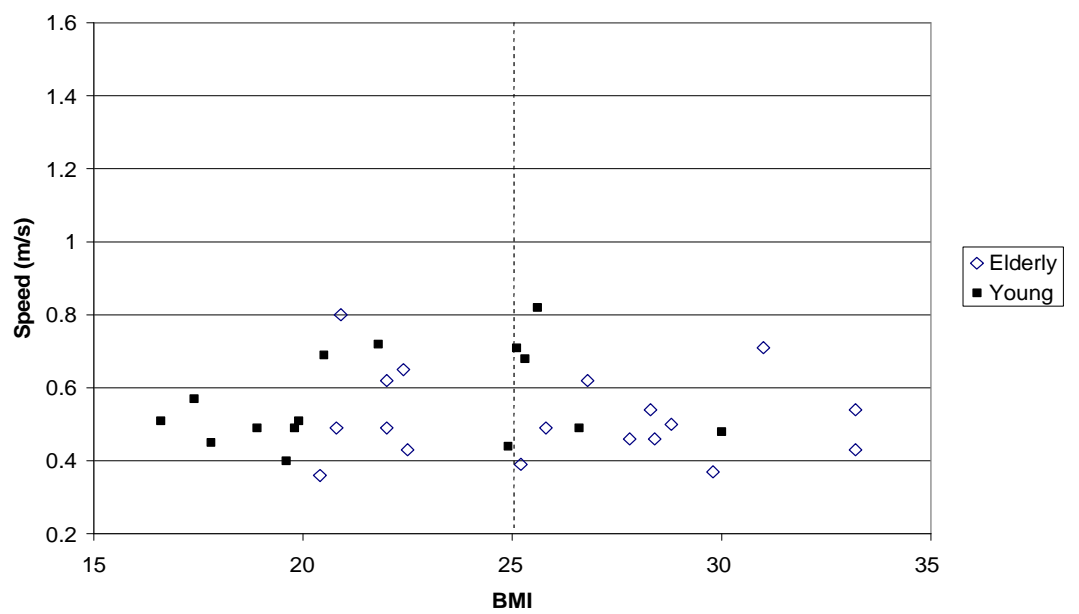

Fig. 5. Relationships between BMI and normal ascending speeds on Staircase 2

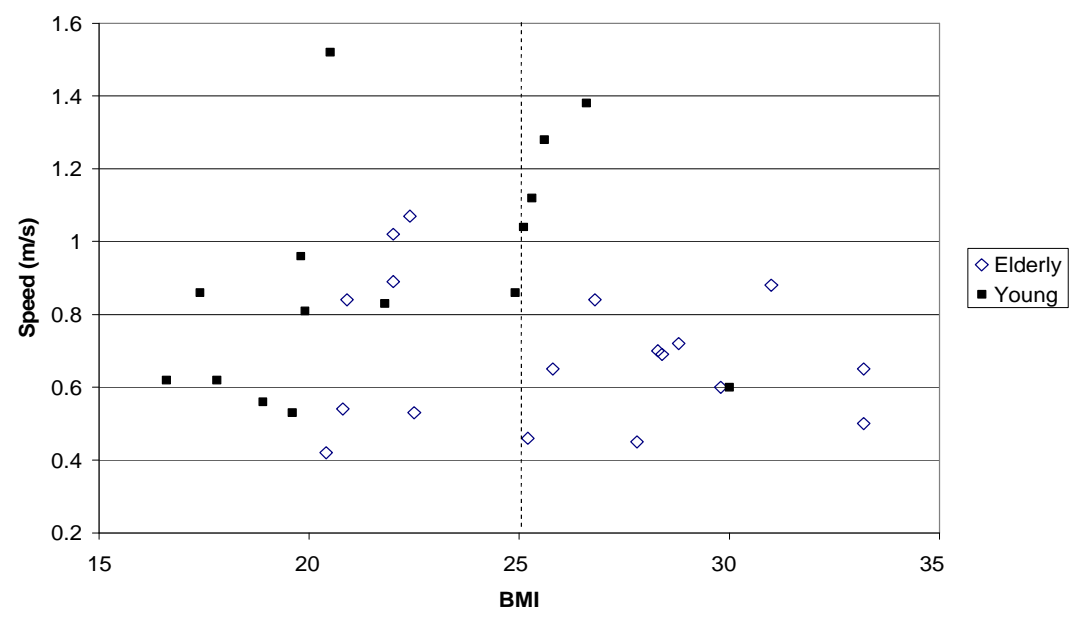

Fig. 6. Relationships between BMI and fast ascending speeds on Staircase 2

Table 3. Profiles of subgroups

\begin{tabular}{lllll}
\hline & Elderly & \multicolumn{3}{l}{ Young } \\
\cline { 2 - 5 } & Normal & Overweight & Normal & Overweight \\
\hline Sample size & 7 & 11 & 10 & 5 \\
\hline Age $(\mathrm{yr})$ & $72.6 \pm 6.7$ & $70.7 \pm 5.6$ & $34.4 \pm 10.8$ & $34.6 \pm 17.2$ \\
\hline BMl $\left(\mathrm{kg} / \mathrm{m}^{2}\right)$ & $21.6 \pm 0.8$ & $28.9 \pm 2.7$ & $19.7 \pm 2.4$ & $26.5 \pm 2.0$ \\
\hline
\end{tabular}

Age and BMI are given as mean \pm SD. 
Figure 7 shows the average normal ascending speeds of each subgroup, whereas Figure 8 shows fast ascending speeds. In the figures, the elderly-overweight subgroup shows a lower value than the elderly-normal subgroup for all the staircases, whereas the young-overweight subgroup shows a higher value. Table 4 compares walking speeds between the subgroups within each group (elderly and young). The standard deviation of each entry is large, and a statistical significance is merely observed.

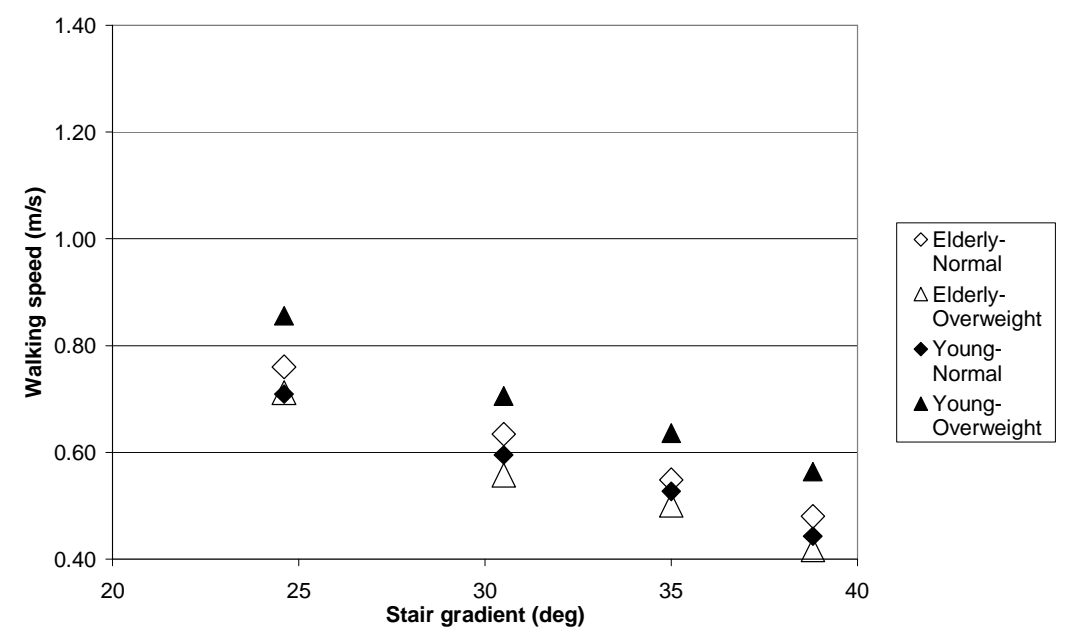

Fig. 7. Average normal ascending speeds of each subgroup by stair gradient

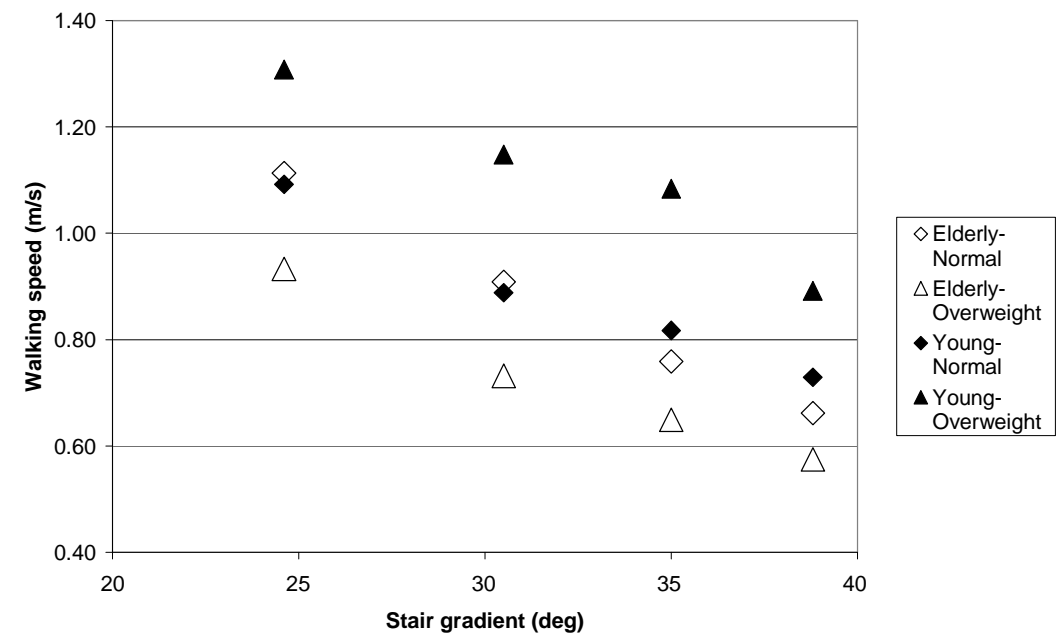

Fig. 8. Average fast ascending speeds of each subgroup by stair gradient 
Table 4. Comparison of walking speeds between subgroups

\begin{tabular}{|c|c|c|c|c|c|c|c|c|}
\hline \multirow{2}{*}{$\begin{array}{l}\text { Patterns of } \\
\text { speeds }\end{array}$} & \multicolumn{2}{|c|}{ Staircase } & \multicolumn{3}{|l|}{ Elderly } & \multicolumn{3}{|l|}{ Young } \\
\hline & No & Degree & Normal & Overweight & $\begin{array}{l}\text { Significance of } \\
\text { Difference }\end{array}$ & Normal & Overweight & $\begin{array}{l}\text { Significance of } \\
\text { Difference }\end{array}$ \\
\hline \multirow{4}{*}{$\begin{array}{l}\text { Normal } \\
\text { ascending }\end{array}$} & Stair 1 & 38.8 & $0.48 \pm 0.15$ & $0.42 \pm 0.09$ & $N S . p=1.13$ & $0.44 \pm 0.18$ & $0.56 \pm 0.11$ & $p<0.05$ \\
\hline & Stair 2 & 35 & $0.55 \pm 0.15$ & $0.50 \pm 0.10$ & NS. $p=0.82$ & $0.53 \pm 0.10$ & $0.64 \pm 0.15$ & $N S . p=1.67$ \\
\hline & Stair 3 & 30.5 & $0.63 \pm 0.15$ & $0.56 \pm 0.11$ & NS. $p=1.25$ & $0.60 \pm 0.10$ & $0.71 \pm 0.19$ & $N S . p=1.51$ \\
\hline & Stair 4 & 24.6 & $0.76 \pm 0.22$ & $0.71 \pm 0.15$ & $N S . p=0.56$ & $0.71 \pm 0.11$ & $0.86 \pm 0.23$ & $N S . p=1.74$ \\
\hline \multirow{4}{*}{$\begin{array}{l}\text { Fast } \\
\text { ascending }\end{array}$} & Stair 1 & 38.8 & $0.66 \pm 0.23$ & $0.57 \pm 0.13$ & NS. $p=1.02$ & $0.73 \pm 0.25$ & $0.89 \pm 0.23$ & $N S . p=1.24$ \\
\hline & Stair 2 & 35 & $0.76 \pm 0.26$ & $0.65 \pm 0.14$ & $N S . p=1.17$ & $0.82 \pm 0.29$ & $1.08 \pm 0.30$ & $N S . p=1.67$ \\
\hline & Stair 3 & 30.5 & $0.91 \pm 0.24$ & $0.73 \pm 0.15$ & NS. $p=1.89$ & $0.89 \pm 0.23$ & $1.15 \pm 0.31$ & $N S . p=1.82$ \\
\hline & Stair 4 & 24.6 & $1.11 \pm 0.30$ & $0.93 \pm 0.16$ & NS. $p=1.69$ & $1.09 \pm 0.27$ & $1.31 \pm 0.38$ & $N S . p=1.29$ \\
\hline \multicolumn{3}{|c|}{$\begin{array}{l}\text { Normal walking on the flat } \\
\text { surface }\end{array}$} & $1.33 \pm 0.24$ & $1.30 \pm 0.24$ & NS. $p=0.25$ & 1.00 & $1.51 \pm 0.13$ & $N S . p=1.79$ \\
\hline \multicolumn{3}{|c|}{$\begin{array}{l}\text { Fast walking on the flat } \\
\text { surface }\end{array}$} & $1.83 \pm 0.31$ & $1.64 \pm 0.26$ & NS. $p=1.35$ & $1.81 \pm 0.18$ & $1.89 \pm 0.07$ & NS. $p=0.98$ \\
\hline
\end{tabular}

\section{Discussions}

\section{a) Stair gradients and walking speeds}

Figure 2 suggests a linear relationship between walking speeds on stairs and stairgradients. The results are in contrast to the fact that many pedestrian simulation models use the same speeds for different stairs with different gradients. When walking speeds on stairs are estimated from speeds on flat surfaces using a reduction coefficient, the stair gradient should be taken into account. In Figure 2, the young group shows a large difference between percentages of ascending speeds and those of descending speeds, whereas the elderly group does not. When pedestrians that consist mainly of young people are simulated, it is recommended to use different coefficients for ascending and descending speeds. So, what value should be used? Readers can refer to the equations in Figures 3 and 4 for normal speeds.

\section{b) Effects of overweight}

In Figures 7 and 8, the elderly-overweight subgroup shows a lower value than the elderly-normal subgroup for all the staircases, whereas the young-overweight subgroup shows a higher value. One possible explanation for this is the components of each overweight subgroup. Because BMI is calculated by weight and height, the index does not distinguish between obese and muscular people. Some professional athletes are even categorised as "overweight" or "obese" [8]. On the other hand, muscle decreases with age [9]. It is speculated that the young-overweight subgroup included muscular people, whereas the elderly-overweight included fat people, and thus the trends are different. 
So, do obese people walk more slowly than people of normal weight? We now focus on walking speeds of elderly people. From Figures 5 and 6, the relationship between BMI and walking speeds is not clear. In Figures 7 and 8, the elderlyoverweight subgroup shows a lower value than the normal subgroup on all the staircases. Table 4 shows that a statistical significance is merely observed. These imply that there is no significant effect of overweight (because of obesity) on walking speeds. Existing studies have found no effect of obesity on walking speeds (e.g. [10]). There have been some studies that suggested such effects, but such studies have used a treadmill (e.g. [11]) or examined the speeds of obese people only and compared them with data of other experiments (e.g. [12]). Our result shows that, even though the average values of the elderly-overweight subgroup are lower than those of the elderly-normal subgroup, the differences were not significant compared to the variations of each subgroup. It is known that for each person, there is one walking speed that minimises the amount of energy required to walk, and his/her preferred walking speed is thought to correspond with this speed [10]. Browning and Kram [10] found that energy consumption in walking of obese people was not as great as physiologists had thought, and suggested that obese people learn to walk in a way that reduces the extra energy consumption due to obesity. Interestingly, Figures 7 and 8 show that differences in fast ascending speeds between elderly-normal and elderly-overweight subgroups were larger than those in normal ascending speeds. One possible reason for this is that because overweight people do not often walk fast, they are not familiar with ways to reduce the extra energy consumption in fast walking.

It should be noted that the overweight-elderly group in our experiment did not include any severely or morbidly obese person with a BMI of 35 or more, who falls into Class II or Class III obesity according to WHO [7]. One study estimated that around $8 \%$ of the population of the USA was Class II or Class III obese in 2005 [13]. Further research would be necessary to investigate walking speeds of severely and morbidly obese people on stairs.

\section{Conclusions}

This study explored the effects of stair gradients and overweight on walking speeds on stairs. The study found that stair gradients affect walking speeds on stairs. In the estimation of walking speeds on stairs based on those on flat surfaces, it is recommended to take account of the stair gradient. The study did not find any 
significant difference between the walking speeds of normal and overweight (or moderately obese) participants. However, further research would be necessary on walking speeds of severely or morbidly obese people. In addition, differences in body size and potential differences in body movement of obese people from those of normal people could affect the capacity of pedestrian flow that includes obese people. Further investigation is necessary on this topic as well.

\section{References}

(Websites and their contents were current on 31 January 2010)

1. Daamen, W. and Hoogendoorn, S. P.: Free speed distribution - Based on empirical data in different traffic conditions" In: N Waldau, P. et al. (Eds.), Pedestrian and evacuation dynamics 2005 (pp. 13-25). Springer, Berlin (2007)

2. Wilson, D. G. and Grayson, G. B.: Age-related differences in the road cross-ing behaviour of adult pedestrians, TRRL Laboratory Report 933, Transport and Road Research Laboratory, Berkshire (1980)

3. Bohannon, R. W.: Comfortable and maximum walking speed of adults aged 20-79 years: reference values and determinants, Age and Ageing, 26, 15-19 (1997)

4. Fruin, J. J.: Pedestrian Planning and Design, (Revised Edition), Elevator World, Inc., Mobile, AL (1987)

5. Templer, J. A.: The staircase: Studies of Hazards, Falls, and Safer Design, MIT Press, MA (1992)

6. Fujiyama, T. and Tyler, N.: An Explicit Study on Walking Speeds of Pedestrians on Stairs", in: Proc. of the 10th International Conference on Mobility and Transport for Elderly and Disabled People, pp 643-652 (2004)

7. World Health Organisation, BMI classification available at http://apps.who.int/bmi/index.jsp?introPage=intro_3.html

8. http://en.wikipedia.org/wiki/Body_mass_index

9. Nair, K.S.: Aging muscle, The American Journal of Clinical Nutrition, 81, 953963 (2005)

10.Browning, R.C. and Kram, R.: Energetic cost and preferred speed of walking in obese vs. normal weight women, Obesity Research, 13(5), 891-899 (2005)

11.Melanson, E.L. et al.: Body mass index and sex influence the energy cost of walking at self-selected speeds, Medicine \& Science in Sports \& Exercise, 35(5 suppl) S183 (2003)

12.Mattsson, E. et al.: Is walking for exercise too exhausting for obese women? International Journal of Obesity and Related Metabolic Disorders, 167, 845$850(2001)$

13.Sturn, R.: Increases in morbid obesity in the USA: 2000-2005, Public Health, 121, 492-496 (2007) 